\title{
Spontaneous Subcutaneous Emphysema with Pneumo-Mediastinum: A Case Report
}

\author{
Anwar Ali Jamali1, Ghulam Mustafa Jamali', Niaz Hussain Jamali ${ }^{*}$ \\ ${ }^{1}$ Department of Medicine Peoples, University of Medical \& Health Sciences, Nawabshah, Pakistan \\ ${ }^{2}$ Department of Physiology Peoples, University of Medical and Health Sciences, Nawabshah, Pakistan \\ Email: ^jamalian warali@gmail.com
}

How to cite this paper: Jamali, A.A., Jamali, G.M. and Jamali, N.H. (2017) Spontaneous Subcutaneous Emphysema with PneumoMediastinum: A Case Report. Case Reports in Clinical Medicine, 6, 285-290. https://doi.org/10.4236/crcm.2017.611032

Received: October 10, 2017

Accepted: November 12, 2017

Published: November 15, 2017

Copyright (c) 2017 by authors and Scientific Research Publishing Inc. This work is licensed under the Creative Commons Attribution International License (CC BY 4.0).

http://creativecommons.org/licenses/by/4.0/

(c) (i) Open Access

\begin{abstract}
Aim: To report a rare case of Spontaneous subcutaneous emphysema and pneumo-mediastinum Introduction: Spontaneous subcutaneous emphysema and pneumo-mediastinum may be defined as the presence of free gas or air in the subcutaneous tissue or mediastinal structures without an apparent precipitating cause. It most commonly occurs in adolescent in good physical health group devoid of severe existing lung pathology. Case Report: In our case, a middle aged married housewife was referred to Department of Medicine, Peoples Medical University Hospital Nawabshah, Sindh, Pakistan, by her local GP for the worsening of her condition due to development of acute neck pain, difficulty in breathing, eating and swallowing (mainly for solid foods) with swelling of neck. She was not complaining of any respiratory symptoms. The chest and neck radiographs showed subcutaneous emphysema and pneumo-mediastinum, there was no any evidence of air leakage from esophagus. She was subsequently put on free fluids, light diet, antibiotics, analgesia and other supportive measures along with close observation. After three days of admission, her clinical symptoms were alleviated to a great extent. She was discharged well from hospital after four days. Conclusion: Spontaneous subcutaneous emphysema with pneumo-mediastinum is medical and surgical emergency. Diagnosis may be made by routine chest X-rays and CT scan of the chest. Prompt diagnosis and immediate management may affect the morbidity and mortality outcomes in this condition.
\end{abstract}

\section{Keywords}

Spontaneous Subcutaneous Emphysema, Pneumo-Mediastinum

\section{Introduction}

Spontaneous subcutaneous emphysema and pneumo-mediastinum is an infre- 
quent clinical state that is characterized by presence of free gases in subcutaneous tissues and mediastinum without an evident etiology, it typically manifests when broncho-alveolar borders becomes weak due to pulmonary diseases [1] [2] [3]. It most commonly occurs in adolescents with good physical health and devoid of any severe existing lung pathology [2]. As per reported through literature, rate of incidence is about 1/12,000 cases admitted in the hospitals [4]. Risk factors are chest trauma or trauma to upper respiratory tract. More reasons for this circumstance are resulting because of ruptured bullae or cavities which are located sub-pleural [1]. Other causes of this clinical condition are after insertion of chest tube or endotracheal intubation, concomitant anatomical, histological, pathological defects in the pulmonary system and certain diseases like pulmonary tuberculosis, pneumonitis, primary or secondary viral or bacterial infections [5]. The common logic behind the development of this condition is due to traumatic burst of broncho-alveolar walls. The Most widely accepted mechanism is rupture of broncho-alveolar walls, than gases rushes into extra alveolar spaces and subcutaneous tissues and sometimes in the mediastinum leading to pneumo-mediastinum or in the pleural space leading to pneumothorax [1]. The diagnosis of Spontaneous subcutaneous emphysema with pneumo-mediastinum was established on the basis of clinical history, examination and with the radiological help. No obvious cause was identified in our case report on chest X-ray and Computed Tomography imaging.

\section{Case Report}

A 40-year-old female of average height and built conscious well oriented was in her usual state of good health. She was referred to Department of Medicine, Peoples Medical University Hospital Nawabshah Sindh Pakistan by her General Practitioner from a remote area. She presented to her GP with history of fever and runny nose, on third day of her illness, she suddenly developed acute neck pain, difficulty in breathing, dysphagia ( mainly for solid foods) and odynophagia with swelling of neck (Figure 1) and she was not complaining of any respiratory symptoms. The above symptoms started without any trauma or precipitating factors. She had no current history of trauma, aspiration of foreign body or drug abuse. There was no any other significant history of medical or surgical disease. On examination she was ill looking, having temperature $36.5^{\circ} \mathrm{C}$, blood pressure $100 / 60 \mathrm{mmHg}$ and the pulse was 80 beats/min regular. There was symmetrical swelling around the neck with crepitations on palpation. The chest evaluation demonstrated symmetrical and bilateral clear breath sounds and normal heart sounds without any murmur but mediastinal crunch was audible on auscultation.

An arterial blood gas analysis on room-air showed: $\mathrm{pH} 7.413, \mathrm{PaO}_{2} 13.59 \mathrm{kpa}$, $\mathrm{PaCO}_{2} 5.40 \mathrm{kpa}, \mathrm{SaO}_{2} 97.9 \%$ and $\mathrm{HCO}_{3} 24.8 \mathrm{mmol} / \mathrm{l}$. The hemoglobin $15.6 \mathrm{~g} / \mathrm{dl}$, hematocrit $43 \%$, the white cell count 11,800 and platelets were 190,000 per cubic $\mathrm{mm}$. The blood chemistry and urinalysis were normal. 


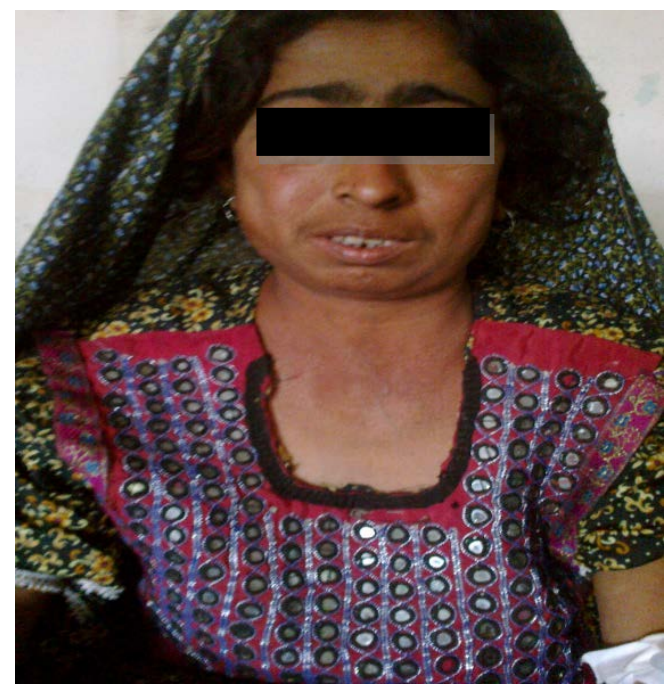

Figure 1. Female with chest, neck and face swelling due to spontaneous subcutaneous emphysema.

The chest and neck radiograph showed subcutaneous emphysema in neck and pneumo-mediastinum (Figure 2) but there was no any evidence of air leakage from esophagus.

She was subsequently put on free fluids, light diet, antibiotics, analgesia and other supportive measures along with close observation. After three days of admission her clinical symptoms were alleviated to a great extent. She was discharged from hospital after four days in a stable state.

\section{Discussion}

This rare case was diagnosed in our ward as spontaneous subcutaneous emphysema with pneumo-mediastinum; this is rare presentation in our setup. Cases have been reported all over the world. The process of air escape from respiratory tract in the start was notified by Macklin but that was a mammal research [6]. Pressure changes create an imbalance between the intra-alveolar and interstitial spaces resulting in escape of air into the adjacent spaces and tissues. Like in our case air leakage was into different spaces/tissues, producing spontaneous subcutaneous emphysema with pneumo-mediastinum, which resulted due to leakage of air from small alveolar openings and alveolar rupture into the adjacent tissues. This pressure difference leads to the development of other symptoms of affected areas like neck pain, difficulty in breathing and dysphagia as seen in our case and previously described by Thawley SE [7]. Lee SK had shown in his study that chest pain, difficulty in breathing and swallowing are the common presentation of this problem, these findings are comparable with our case [8].

Neck and chest examination revealed swelling around the neck with crepitation on palpation. The chest evaluation demonstrated symmetrical and bilateral clear breath sounds and normal heart sounds without any murmur but mediastinal crunch was audible on auscultation. These findings were also matching 


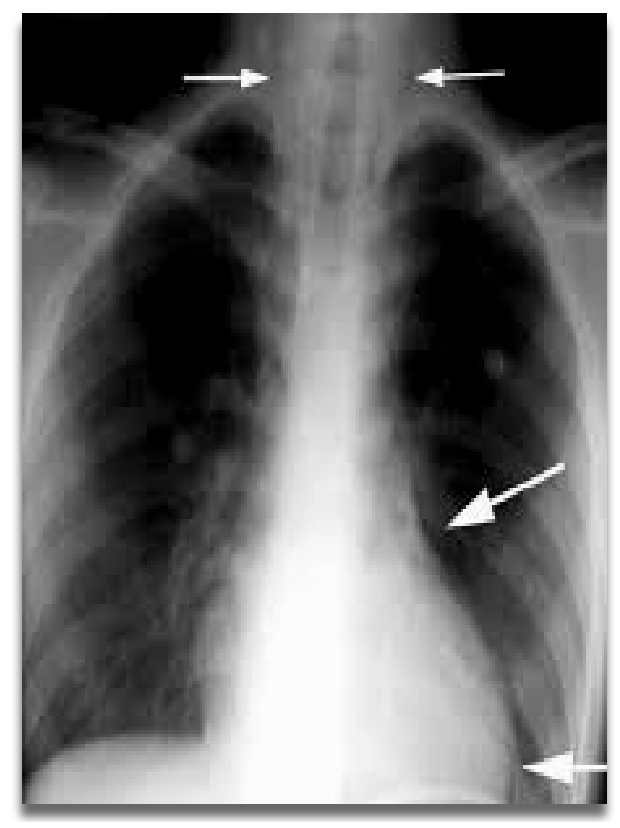

Figure 2. X-ray chest (PA) view showing subcutaneous emphysema (neck arrow) and pneumo-mediastinum (chest arrow).

with the findings in a study by Gossage AR et al. [9] and Walsh-Kelly C [10]. As fever was the initial presentation along with increased WBC count in our case, the findings of the study done by Ralph-Edwards $\mathrm{C}$ were also supporting our case study [11]. Esophageal rupture may be associated with any increase in abdominal pressure, including childbirth, seizures, load uplift or sudden trauma to abdomen as described by Thawley SE [7]. Clinical findings in our case were not in favor of esophageal rupture because she was a non-smoker house wife and there was no history of alcoholism, retching, hyper emesis, raised intra abdominal pressure due to child delivery and fits. In our study the Spontaneous subcutaneous emphysema with mediastinal emphysema was observed with chest pain, difficulty in breathing and swallowing along with cough, restlessness, swelling around the neck face and chest [7] [10]. Subcutaneous emphysema with mediastinal emphysema usually occurs in asthmatic patients there is spontaneous recovery of symptoms with supporting therapy. In children suffering from bronchial asthma recurrent problems can occur, so management of bronchial asthma is valuable step in these subjects. Nowadays screening the deficiency of Alpha1-antitrypsin is proposed to rule out the important cause of this condition. [12] [13]. X-ray chest PA and lateral views are the best initial imaging investigations to diagnose the subcutaneous emphysema with pneumo-mediastinum. $\mathrm{X}$-ray findings in our case are numerous air pockets in the subcutaneous areas and a clear streak shadow of air in the mediastinum suggestive of pneumo-mediastinum, $\mathrm{X}$-ray findings in our case are greatly matching with the finding of Kim SH et al., who described that Chest X-ray is a sensitive initial investigation tool and may illustrate multiple thin, lucent streaks outlining mediastinal 
structures, elevating the mediastinal pleura and often extending into the neck or chest wall in half of cases and with half missing due to small volume of air [14]. For the confirmation of the diagnosis, X-ray chest was best initial modality but it is now replaced with chest Computed Tomography scanning. It was advised as it is next best investigation, but results were not conclusive to identify the exact cause of this condition. Saracino and Tessaro compared findings of chest CT scan with chest X-rays and concluded CT scan as a more sensitive radiological method [15].

In most of the cases where imaging and other techniques are available it is convenient to diagnose the exact etiology and pathophysiology of this condition but our setup deficits advance measures in relation to diagnosis. It is usually under diagnosed or misdiagnosed. It is self-limited and resolves spontaneously and treatment is mainly supportive with the bed rest, antibiotics, analgesia and oxygen. Management of Spontaneous subcutaneous emphysema with mediastinal emphysema is generally a careful and close monitoring of the patient because mostly gases dissolve in the tissues with the passage of time, usually within one month or less duration [14].

Nicking and milking along piercing with the needles were old traditional methods and should be avoided in health units where facilities for management are available, because of risk to inoculate the serious life threatening infections. In some situations when the life is in danger emergent treacheostomy with or without skin deep nicking may be necessary over the chest and neck. Some patients even need more modern interventions to save the life [11] [15] [16].

\section{Conclusion}

Spontaneous subcutaneous emphysema with pneumo-mediastinum is medical and surgical emergency. Diagnosis may be made by routine chest X-rays and CT scan chest. These patients should be started immediately on the general supportive management with broad spectrum antibiotics mainly and with immediate consultant opinion from cardiothoracic surgeon. Prompt diagnosis and immediate management may affect the morbidity and mortality outcomes in this condition.

\section{Funding}

The authors received no financial support for the research, authorship, and/or publication of this article.

\section{Conflict of Interest}

The authors declared no potential conflicts of interest with respect to the research, authorship, and/or publication of this article.

\section{References}

[1] Venugopal, K., Reddy, M.M., Bharathraj, Y.M. and Kadappa, J. (2015) Non-Traumatic, 
Spontaneous Subcutaneous Emphysema: Diagnostic and Therapeutic Dilemma. International Journal of Health \& Allied Sciences, 4, 97-99.

http://www.ijhas.in/text.asp?2015/4/2/97/154910

[2] Munsell, W.P. (1967) Pneumomediastinum: A Report of 28 Cases and a Review of the Literature. JAMA, 202, 689-693.

https://doi.org/10.1001/jama.1967.03130210063009

[3] Young-Jung, L., et al. (2001) A Case of Spontaneous Pneumomediastinum and Pneumopericardium in a Young Adult. The Korean Journal of Internal Medicine, 16, 205-209. https://doi.org/10.3904/kjim.2001.16.3.205

[4] Yellin, A., Gapany-Gapanavivius, M. and Lieberman, Y. (1983) Spontaneous Pneumomediastinum; Is It a Cause of Chest Pain? Thorax, 38, 383-385.

https://doi.org/10.1136/thx.38.5.383

[5] Das, M., Chandra, U., Natchu, M., Lodha, R. and Kabra, S.K. (2004) Pneumomediastinum and Subcutaneous Emphysema in Acute Miliary Tuberculosis. The Indian Journal of Pediatrics, 71, 553-554. https://doi.org/10.1007/BF02724303

[6] Maclin, C.C. (1939) Transport of Air along Sheats of Pulmonic Blood Vessels from Alveoli to Mediastinum: Clinical Implication. Archives of Internal Medicine, 64, 913-926. https://doi.org/10.1001/archinte.1939.00190050019003

[7] Thawley, S.E. (1974) Air in the Neck. The Laryngoscope, 84, 1445-1453. https://doi.org/10.1288/00005537-197409000-00001

[8] Lee, S.K., Im, J.S. and Cho, N.S. (1995) Clinical Evaluation of Pneumomediastinum in Adult. The Korean Journal of Thoracic and Cardiovascular Surgery, 28, 1150-1154.

[9] Gossage, A.R. and Robertson, P.W. (1976) Spontaneous Pneumomediastinum. Thorax, 31, 460-465. https://doi.org/10.1136/thx.31.4.460

[10] Walsh-Kelly, C. and Kelly, K.J. (1986) Dysphonia: An Unusual Presentation of Spontaneous Pneumomediastinum. Pediatric Emerg Care., 2, 26-27. https://doi.org/10.1097/00006565-198603000-00008

[11] Ralph-Edwards, C. and Pearson, F.G. (1994) A Typical Presentation of Spontaneous Pneumomediastinum. The Annals of Thoracic Surgery, 58, 1758-1760. https://doi.org/10.1016/0003-4975(94)91683-7

[12] Siri, D., Farah, H. and Hogarth, D. (2013) Distinguishing Alpha1-Antitrypsin Deficiency from Asthma. Annals of Allergy, Asthma \& Immunology, 111, 458-464. https://doi.org/10.1016/j.anai.2013.09.019

[13] Craig, T. (2015) Suspecting and Testing for Alpha-1 Antitrypsin Deficiency-An Allergist's and/or Immunologist's Perspective. The Journal of Allergy and Clinical Immunology: In Practice, 3, 506-511. https://doi.org/10.1016/j.jaip.2015.04.005

[14] Kim, S.H., et al. (1998) Spontaneous Pneumomediastinum on CT: Related Condition and Its Clinical Signification. Journal of the Korean Society of Radiology, 38, 459-462. https://doi.org/10.3348/jkrs.1998.38.3.459

[15] Saracino, C. and Tessaro, M. (2015) Pneumomediastinum as a Sonographic Mimic of Pneumothorax. Journal of Ultrasound in Medicine, 34, 1521-1522. https://doi.org/10.7863/ultra.34.8.1521

[16] Rumack, C.M., Wilson, S.R., Char-Boneau, J.W. and Levine, D. (2011) Diagnostic Ultrasound. 4th Edition, Elsevier Canada, Etobicoke. 